\title{
ESTUDO ANTROPOLÓGICO SOBRE A CONSTRUÇÃO DE UMA INTIMIDADE FEMININA ATRAVÉS DA PUBLICIDADE E PROPAGANDA
}

\author{
Januária Monteiro Menegotto \\ Orientação Ana Luiza Carvalho da Rocha
}

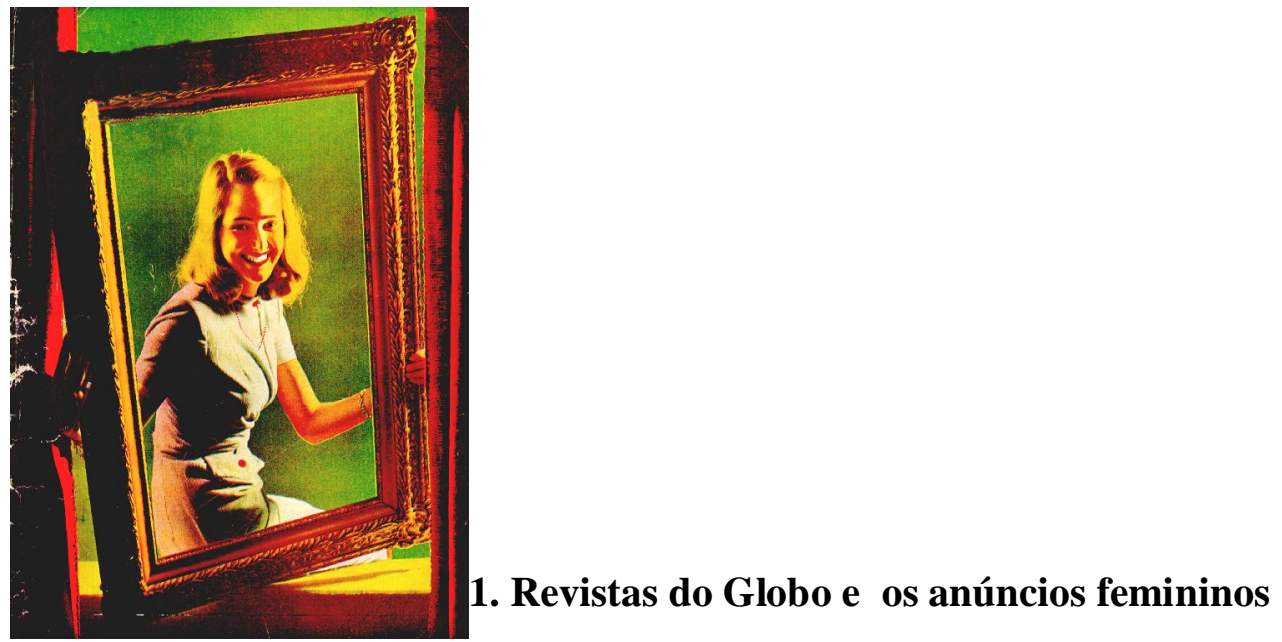

Quando iniciei meu trabalho com as Revistas do Globo no Banco de Imagens e Efeitos Visuais não tinha muita idéia das possibilidades e das "revelações" que encontraria dentro daquelas velhas e amareladas revistas. As primeiras imagens a serem cadastradas já me despertavam muitas dúvidas e curiosidades a respeito da vida da época, suas sociabilidades, seus grupos, seus padrões, seus estilos de vida... Aos poucos, trabalhando mais especificamente com os anúncios publicitários, fui percebendo que ali habitavam, de forma muito evidente, personagens ímpares, apresentados a partir de uma forma discursiva particular... Eram elas, as mulheres dos anúncios.

Rostos delicados, discretamente maquiados, unhas perfeitas, não raro vermelhas, - o que se podia perceber mesmo as figuras sendo em preto e branco- corpos bem curvados, com seios e quadris fartos, mas a cintura finíssima, denunciando o espartilho, tão em moda na década de 50. As propagandas diziam respeito basicamente a quatro esferas da vida social: o lar, a família, a higiene e a beleza. 

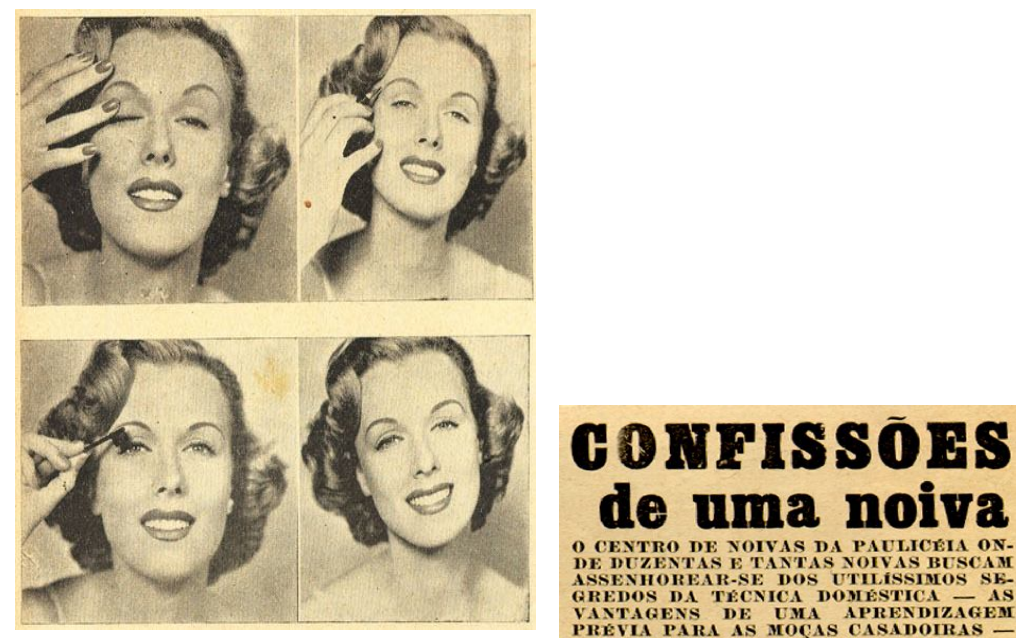

o CENTRO DE NOIVAS DA PAULICEIA ON-

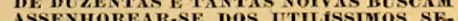
GREDOS DA TECNICA DOMESTICA AS AS VAYTAGENS DE UMA APRENDIZAGEM
PREYA PARA AS MOCAS CASADOIRAS -

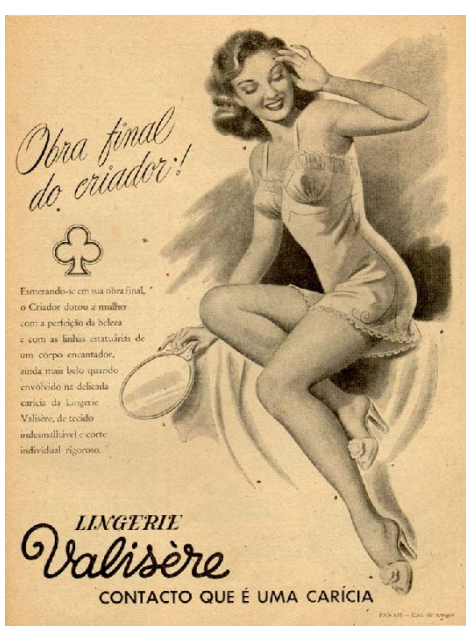
que tudo viŕ́ dalé para mim. e nada dependerá do mim

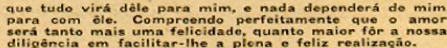

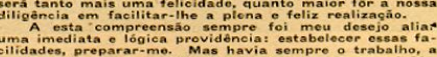

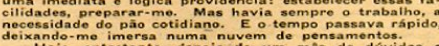
Hojo entretanto depoio de um mens de dúvidas.

Revistas do Globo, com suas reportagens e anúncios, revelando um universo feminino em transformação, no período de 40 a 60 , caracterizado por novos projetos sociais e individuais, mas também por velhos tabus, padrões e preconceitos relativos ao papel da mulher na sociedade.
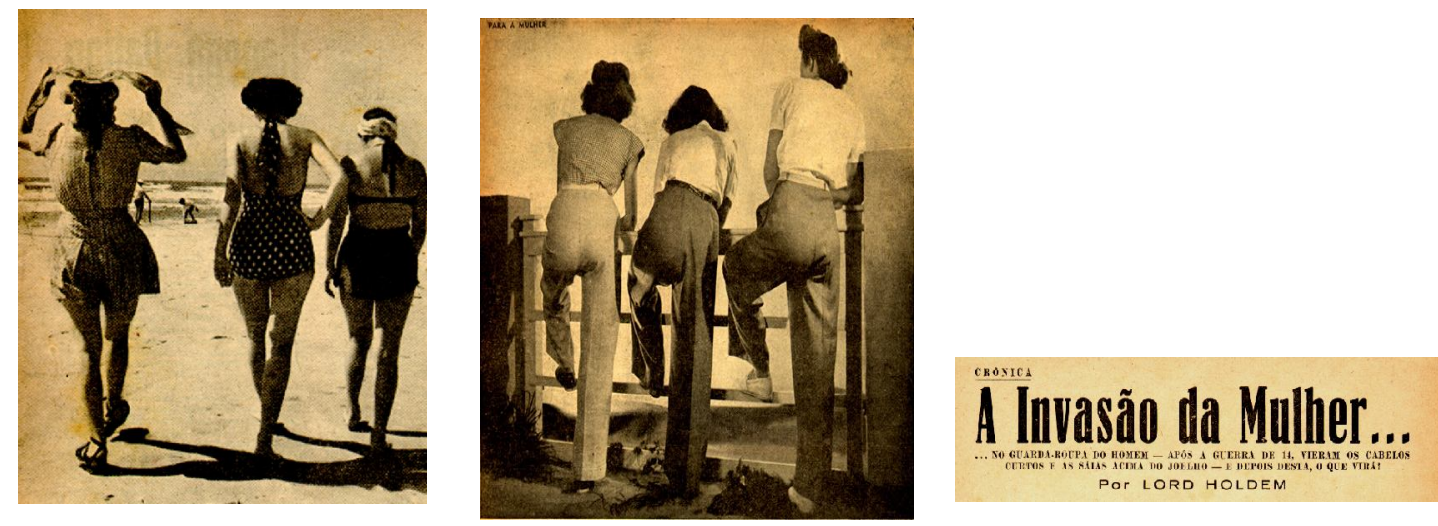

As sociedades complexas moderno-contemporâneas, através do processo de industrialização, se constituem por um maior número de indivíduos, consequiência do desenvolvimento das forças produtivas. E é no cotidiano das grandes metrópoles que encontraremos a evidente expressão desse modo de vida, composto por uma diversidade de 
ostumes e experiências, e onde verificaremos a "fragmentação e diferenciação de papéis e domínios, dando um contorno particular à vida psicológica individual” (G. Velho, 1987).
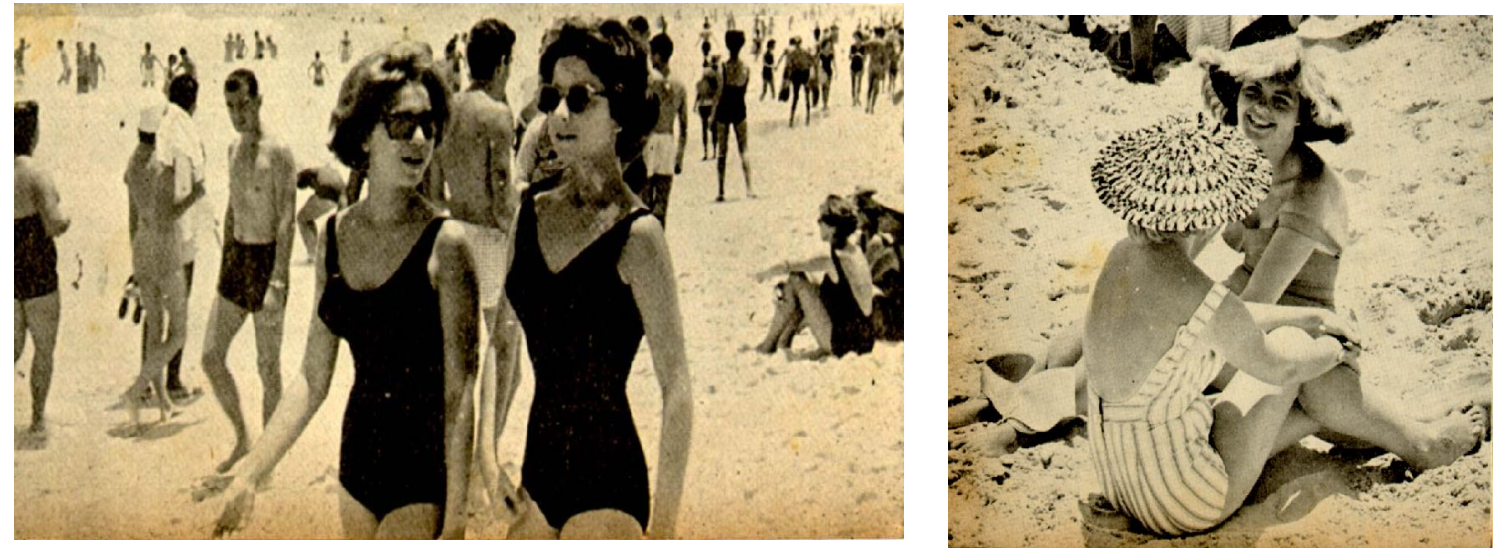

Assim que, vivendo hoje, numa época de crise das antigas ordens de representações e de saberes e, mais profundamente, num tempo de grande complexidade no que diz respeito às formas de produção de identidades sociais, assistimos simultânea e, consequentemente, a um avanço, relacionado à autonomia sexual feminina: a mulher conquistando espaços, mas especialmente, redimensionando o seu espaço público e privado.

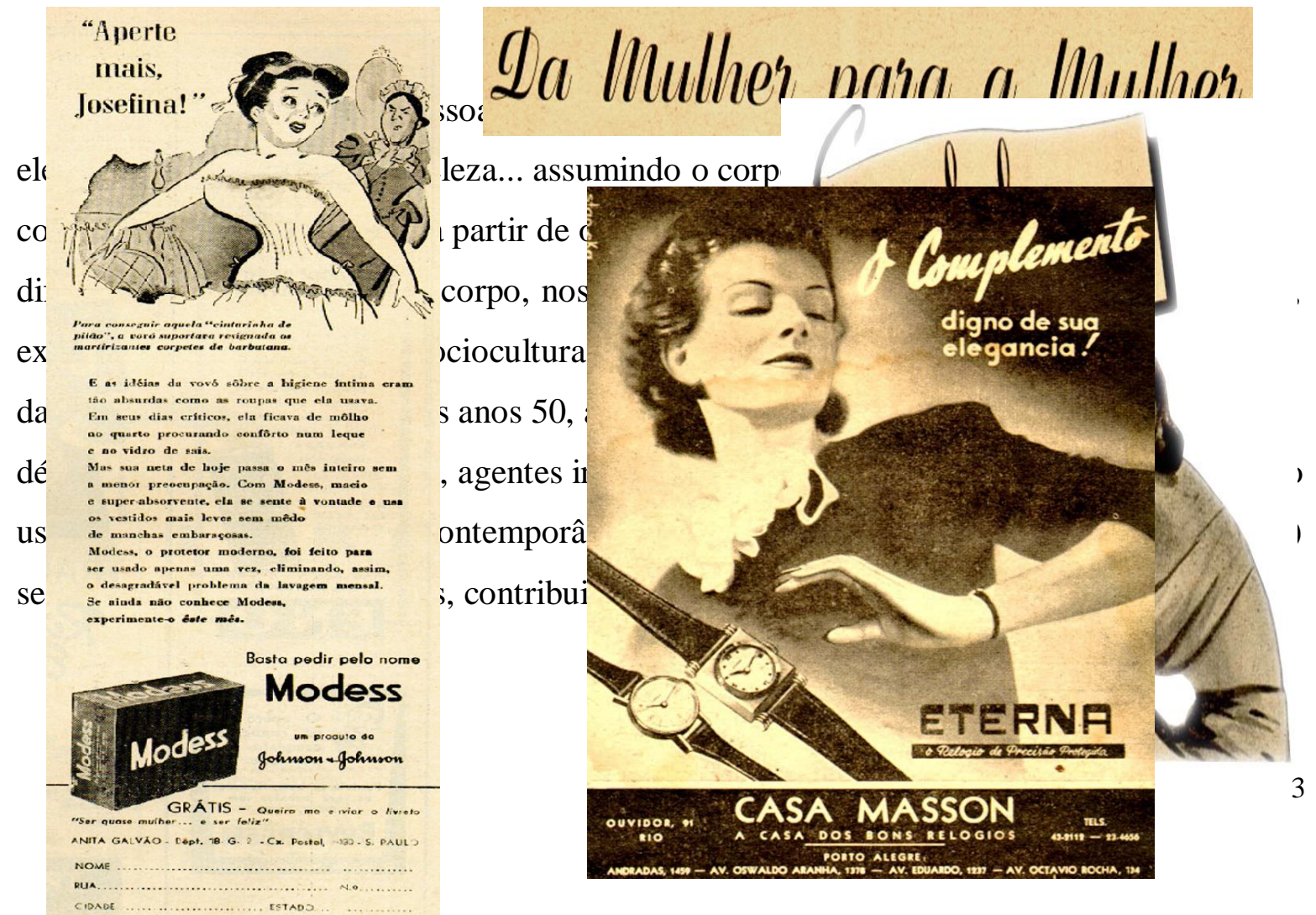


Também na esfera sociopolítica muitas mudanças ocorreram. Movimentos sociais liderados por mulheres, lutando pela libertação de uma condição oprimida, de invisibilidade no espaço público. Conquistou-se o direito ao voto, reconheceu-se a condição da mulher como trabalhadora, leis foram criadas e uma identidade, que não a do âmbito privado, surgiu. Entretanto, a participação política feminina sempre era, e ainda é, inferior à dos homens. Mesmo com essa avalanche de transformações, a imprensa convencional, e a propaganda ainda mais, camuflavam os novos "papéis sociais" adquiridos pelo sexo feminino.

\section{Comportamento Feminino e os anos 40, 50 e 60}

O processo de democratização da vida política, isto é, da esfera pública, foi, primeiramente um projeto masculino, mas que as mulheres, através de sua luta conseguiram participar. A democratização da vida pessoal, todavia, é um processo menos perceptível, uma vez que, além de não acontecer na área pública, possui implicações bastante profundas. Nesse curso da esfera íntima as mulheres, sem dúvida desempenharam um papel fundamental, mesmo que os benefícios alcançados estejam abertos a todos.
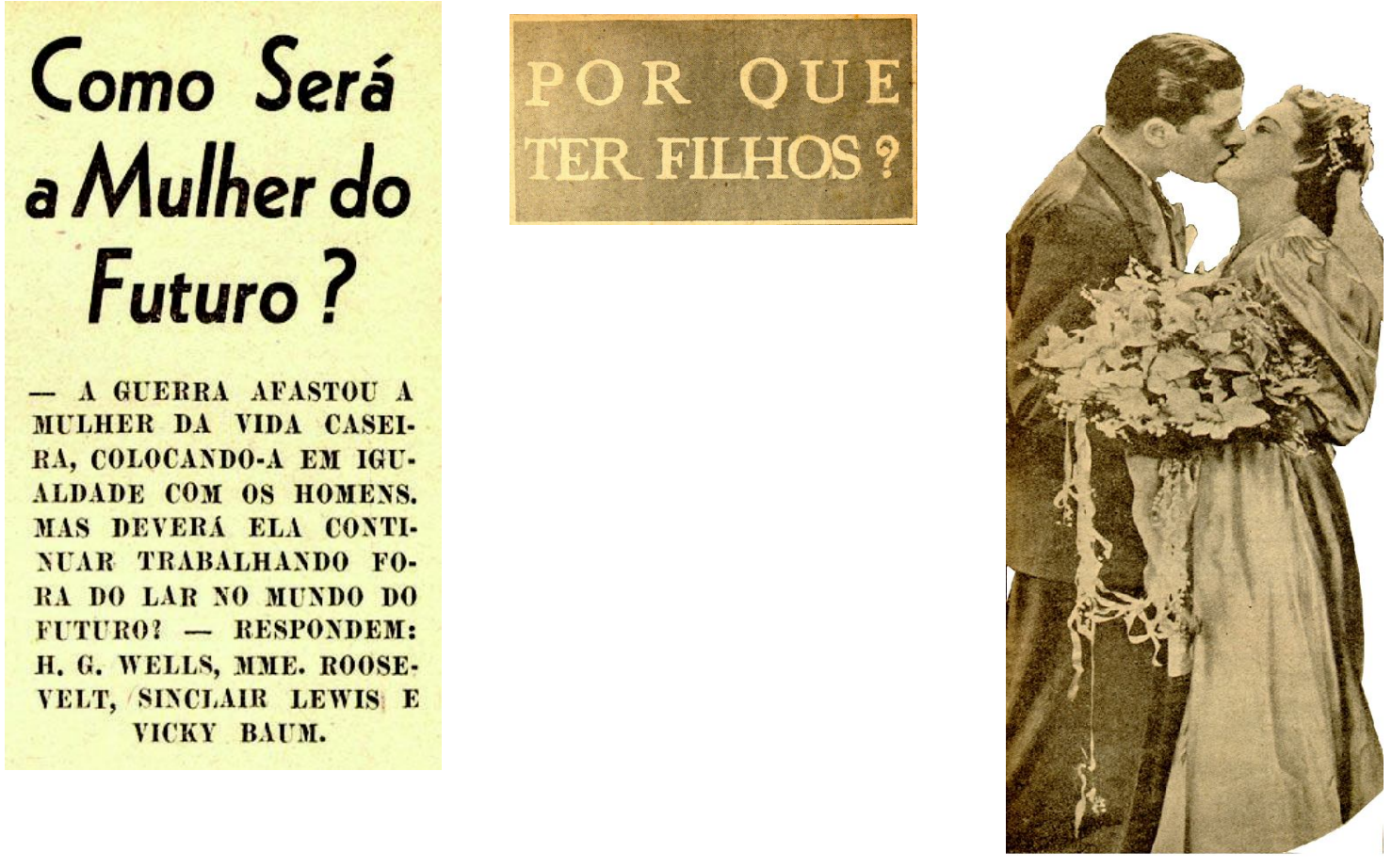
$\mathrm{Na}$ sociedade contemporânea, as imagens da mulher podem ser vistas como parte do processo de reorganização da sexualidade- processo que envolve alteração e construção negociada de masculinidade e feminilidade. Se os sexos e as identidades sexuais são construídas a partir de práticas discursivas diferentes, pode haver, portanto, definições diferenciadas de feminilidade, que podem ser encontradas em variados discursos culturais. Na publicidade, a imagem feminina é utilizada para objetivos bem particulares nem sempre favoráveis à mulher como sujeito.

$\mathrm{Na}$ verdade, o gênero não é atribuído apenas como fato corporal, mas também como conseqüência de uma construção cultural que faz do tornar-se mulher um conjunto de atos intencionais. A
propaganda destinada às mulheres de classe média, todavia, contribui para a incorporação de um significado corpóreo culturalmente estabelecido. Mais do que isso. Os anúncios, em sua maioria, não consideram a interpenetração das diferentes esferas da vida social, isto é, eliminam a possibilidade de construção de identidade e de elaboração de um projeto individual feitos a partir deste contexto de diferentes "mundos".

Se nos anúncios de publicidade temos a subjetividade da mulher unicamente formada como
condição comum, ligada exclusivamente à família, ao lar
e aos cuidados com a beleza, poder-se-ia concluir que ela
é inexistente no domínio público, ocupando apenas, parte
do domínio privado.
Entretanto, as sucessivas mudanças na sociedade 
$\mathrm{Na}$ verdade, o processo de transformações inicia, ainda que manso, na segunda metade do século XIX com o crescimento da cafeicultura, da exportação e do mercado interno brasileiro, como afirma Maria Celia Paoli:

"Esse mundo começa a mudar, lentamente, em seu funcionamento rude $e$ direto(...) Mas enquanto ele existiu de modo dominante, definiu a experiência feminina como subalterna e secundária a partir do forte parâmetro dado pelo senhor cidadão.”

Mas é na década de 30, com o surgimento do Estado Novo, que esta subalternidade foi redefinida. A representação da mulher como figura social foi modificada a partir de conquistas relacionadas à nova legislação, como a limitação da jornada de trabalho, o direito à licença por gravidez, entre outras. Mesmo que tais direitos não digam diretamente respeito à mulher de classe média, dona de casa, eles são prova de um espaço que se conquistava, ainda que não fossem respeitados na prática.

\section{Anúncios e reportagens e o Brasil dos anos 40, 50 e 60}

Em meio a tantas mudanças, a Revista do Globo não poderia ficar alheia. Mesmo que os meios de comunicação, em especial a publicidade, tentem conservar uma imagem feminina já padronizada, é inevitável que acompanhem, ainda que não no mesmo ritmo, o processo que ocorria.

Investigando mais a fundo o conteúdo das revistas, pode-se observar alguns contrastes no que diz respeito às reportagens. Se por um lado, têm-se anúncios que figuram uma mulher idealizada, limitada à esfera privada do lar e à sua própria intimidade, por outro, começam a surgir matérias ligadas às transformações sociais da época. 


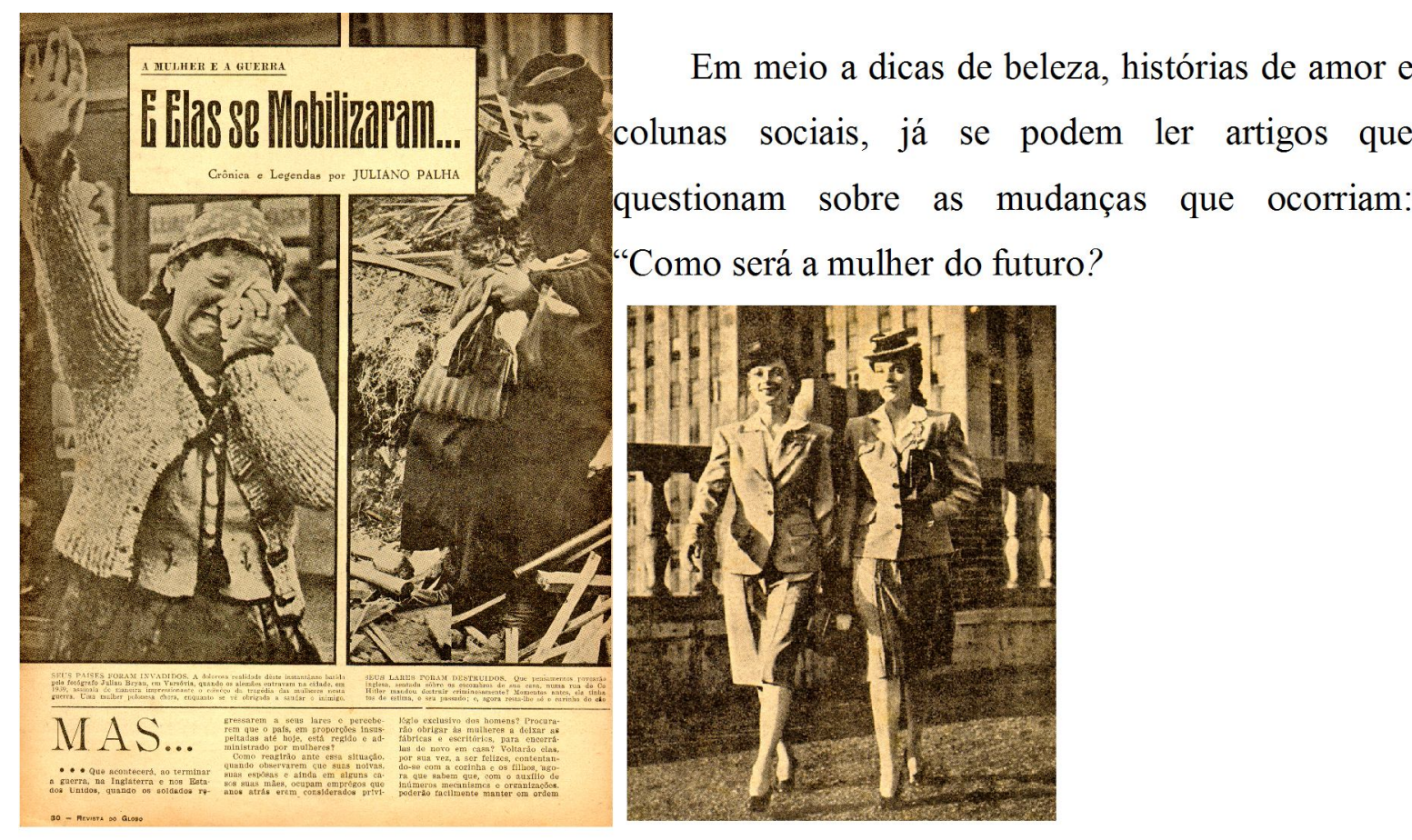

A guerra afastou a mulher da vida caseira, colocando-a em iguladade com os homens, mas deverá ela continuar trabalhando fora do lar no mundo do futuro?"(Revista do Globo).

A mídia, finalmente, passa a retratar um mundo na qual a mulher não é invisível politicamente, ao contrário, exerce um papel fundamental nos processos externos- sociais, políticos, econômicos... mesmo que ainda ocupando uma condição de opressão.

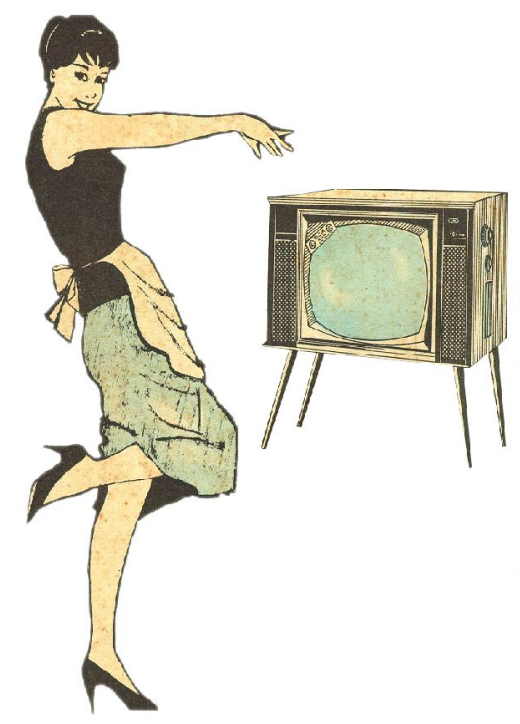

4. Os anúncios de produtos de gênero nas Revistas do Globo

Nas propagandas destinadas ao público feminino encontramos sempre uma mulher com a aparência impecável, com ar sereno, sóbrio, eventualmente sensual, 
mas nunca erotizada. Os cabelos estão quase sempre presos, os lábios pintados, a pele clara- não eram fotografadas ou desenhadas modelos negras- e os olhos discretamente maquiados. Quase todos os anúncios são em preto e branco, compostos por foto ou desenho e por um texto em primeira e/ou segunda pessoa.

Neles, ficam evidentes os papéis representados pela mulher na sociedade da época e os locais onde acontecem suas sociabilidades.

Segue abaixo, a descrição mais detalhada, e ainda dividida em categorias de produtos, dos anúncios analisados no presente trabalho.

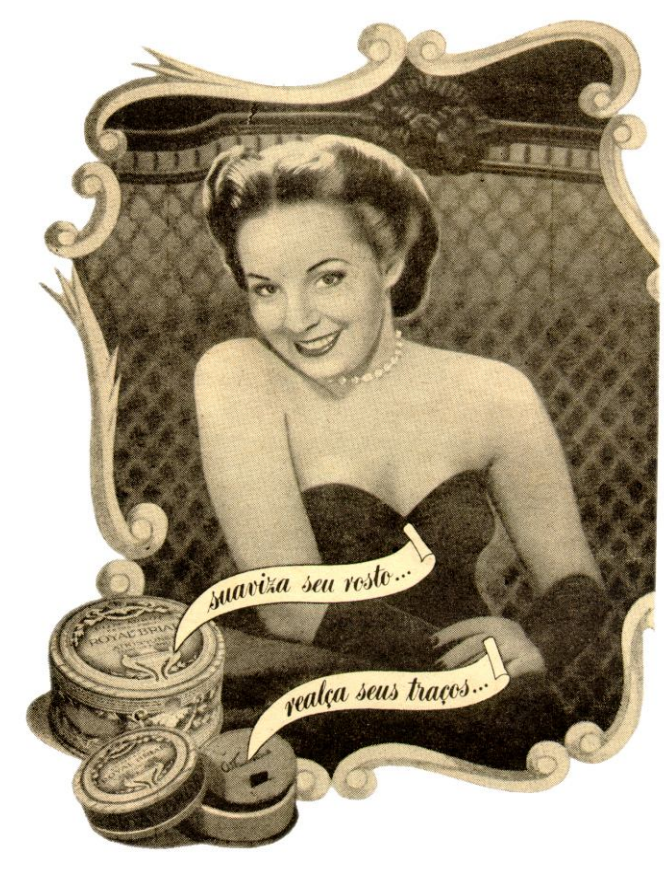

- Cosméticos e higiene pessoal:

Com um texto em segunda pessoa, muitas vezes dirigido à "senhora", os anúncios de cosméticos e de higiene íntima são os que se pode encontrar em maior quantidade nas revistas. Grande parte é composta por desenho ou fotografia de mulheres e por um texto que se dirige diretamente à consumidora, ou ainda, é composto por depoimentos fictícios ou de atrizes famosas como Tônia Carrero, Emilinha Borba, Dulcina de Moraes...(SABONETE EUCALOL).

Tais propagandas se repetem quanto a argumentação, isto é, quanto ao foco de persuasão. Podem garantir o poder da sedução: "ele vai gostar”(pó de arroz ECLAT), "use esta noite”, "o perfume seduz"(ROYAL BRIAR); prometer a beleza desejada: "traga a sua beleza à flor da pele (Ponds)”, “ o embelezador da mulher” (LEITE DE COLÔNIA); ou então, suprimir inseguranças femininas: "Aproxima-se o dia do meu casamento... e, até agora usei o maquillage para ocultar do meu noivo a s imperfeições da pele(...) Poderei iludir o meu marido amanhã?"(LEITE DE COLÔNIA), “Abandonada por causa do C.C.(cheiro de corpo)?” ). Mas, independentemente destas diferenças, sempre encontraremos nos anúncios de cosméticas uma preocupação, se não submissão, com o sexo masculino. 


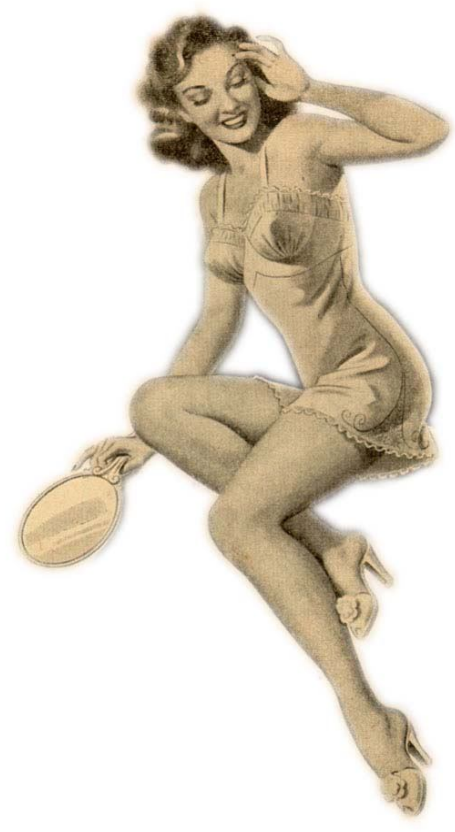

- Lingerie:

Nesta categoria, toda a publicidade anunciada na Revistas do Globo, entre as décadas de 40 e 60 , é da marca VALISÈRE. Talvez este fato se dê devido a uma restrição de mercado, por insuficiência de marcas à altura da concorrência, ou ainda por se tratar de um produto por demais relacionado à intimidade e sexualidade.

Os anúncios são bastante variados, mas seguem a mesma linha de criação, tendo, assim, uma estética bastante semelhante. Lindas mulheres, desenhadas, com um discreto apelo sensual, vestem as peças íntimas-citar nomes das peças- deixando à mostra partes do corpo: uma inovação na "imaculável" mídia.

A figura feminina não aparece, aqui, em um ambiente específico- quarto, cozinha, banheiro, locais públicos- como nos anúncios de outras categorias de produtos, ela se encontra em um "espaço aberto", sem um cenário caracterizado, viabilizando, desta forma, que a consumidora idealize, através da imaginação e da escolha, onde desejaria estar com aquelas vestimentas.

Os anúncios de lingerie VALISÈRE podem ser considerados, se não ousados, inovadores para a época. Corpo à mostra, sensualidade e possibilidade de inventar um universo próprio, são fatores que representam uma mulher que emerge de um mundo no qual desempenha, unicamente, o papel de mãe, esposa e dona de casa, para projetar e articular um projeto próprio.

\section{- Gêneros alimentícios e utilidades domésticas:}

Estas duas categorias apresentam a mulher de forma bastante semelhante. Saia na altura do joelho e camisa ajustada ao corpo sob um avental, evidenciando as obrigações relacionadas ao lar e à família. Também o ambiente explicita estas obrigações, a cena se dá 
sempre na cozinha, ou locais ligados a afazeres domésticos, como lavanderia e supermercado.
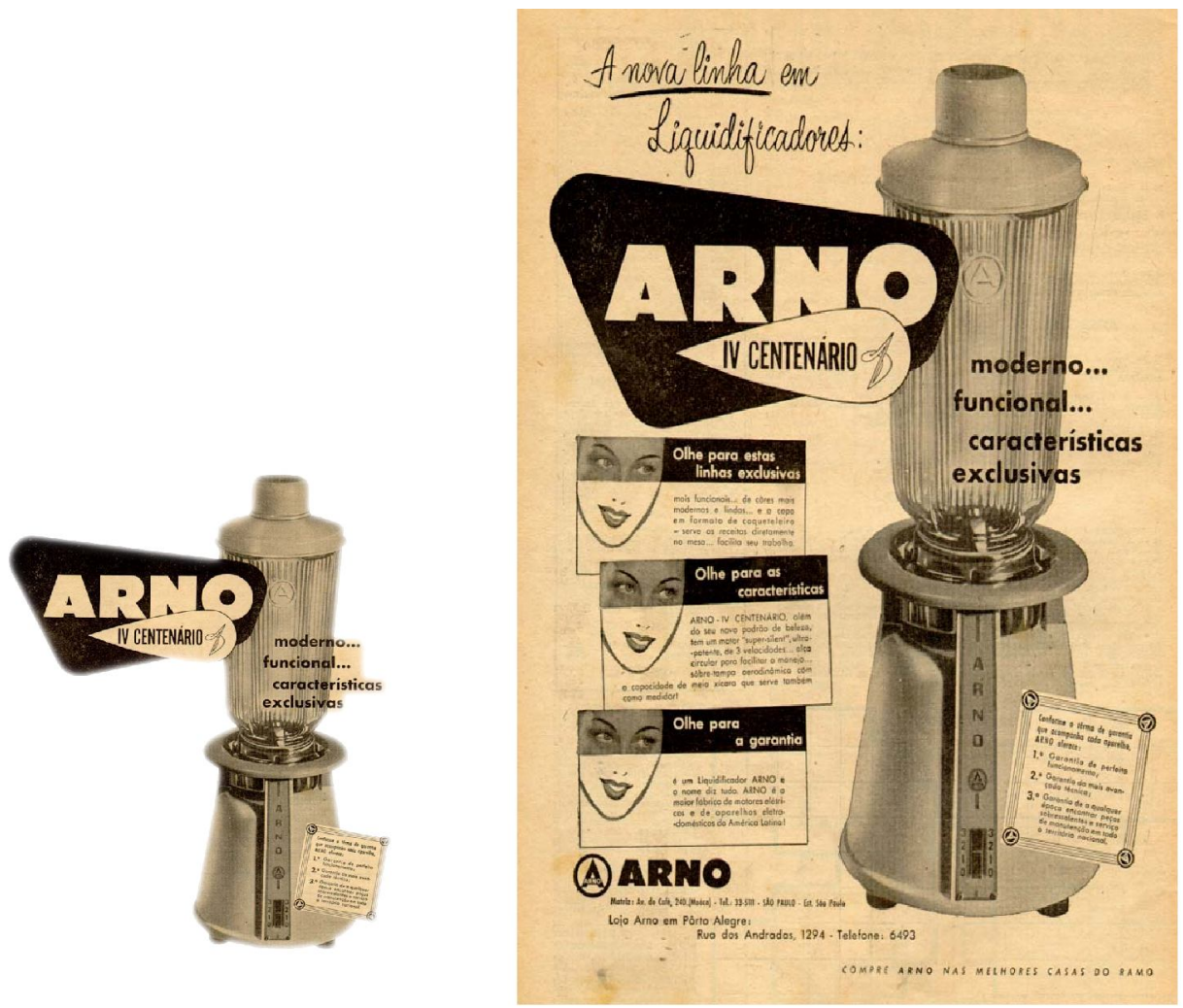

\section{A guisa de Conclusão}

Para que se entenda melhor o universo feminino nas sociedades moderno-contemporâneas, através de anúncios publicitários e reportagens publicados na Revista do Globo das décadas de $30,40,50$ e 60, é preciso, inicialmente, que se esclareçam questões relacionadas ao comportamento da mulher nas épocas estudadas e seu papel na sociedade, além de se verificar todas as características da publicidade de produtos de beleza, higiene, lingerie, utilidades domésticas e gêneros alimentícios, bem como os assuntos tratados nos artigos das revistas. A partir disso, pode-se compreender como se deu, e se dá, a construção de um gênero e de uma identidade feminina. 


\section{Referências}

BAUDRILLARD, Jean. A Sociedade de consumo. São Paulo, Edições 70.

ELIAS,Norbert. A Sociedade dos Indivíduos. Rio de Janeiro, Jorge Zahar, 1994.GIDDENS, Anthony. A Transformação da Intimidade. São Paulo, UNESP,1992.

MAUSS, Marcel. Sociologia e Antropologia. São Paulo, E.P.U., 1974,pp.211-231.

MITCHEL, Juliet. Psicanálise e Feminismo. Belo Horizonte, Interlivros,1979,pp.418-424.

PAOLI, Maria Celia. Mulheres: lugar, imagem, movimento. In: Perspectivas Antropológicas da Mulher-sobre mulher e violência. Rio de Janeiro, Zahar, 1985.

VELHO, Gilberto. Individualismo e Cultura. Rio de Janeiro, Jorge Zahar, 1987.

\section{Imagens}

Revista do Globo

Acervo do banco de imagens digitais do BIEV/Banco de Imanges e Efeitos Visuais 